Physical Therapy Journal of Indonesia (PTJI) 2021, Volume 2, Number 2: 36-40

E-ISSN : 2722-6034; P-ISSN : 2722-0125

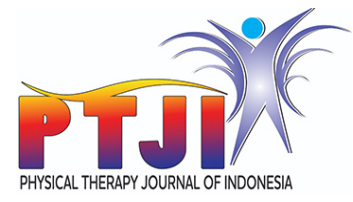

\title{
The Effectiveness of Progressive Muscle Relaxation in Reducing Anxiety and Sleep Disturbances in Hospitalized COVID-19 Patients: A Narrative Review
}

\author{
Muammar Ihsan ${ }^{1 *}$, Luh Putu Miyako Mutiara Sari ${ }^{1}$, \\ Tabita Febyola Wijaya', Desi Mevlana Saputri ${ }^{1}$
}

\begin{abstract}
Introduction: Coronavirus disease (COVID-19) has spread rapidly and massively from China to the rest of the world. Many of the hospitalized COVID-19 patients suffered from psychiatric symptoms such as anxiety and sleep disturbances, besides physical symptoms. Treatment of the psychiatric symptoms commonly used sedative, hypnotic, and anti-anxiety drugs. However, these drugs have some side effects. As an alternative, non-pharmacological intervention is needed. Some previous studies have shown that progressive muscle relaxation (PMR) can improve anxiety levels and sleep quality in other hospitalized patients. Therefore, this study was conducted to determine the effectiveness of PMR in hospitalized COVID-19 patients who experienced anxiety and sleep disturbances.

Methods: We conducted a narrative review by searching for studies through PubMed and Google Scholar database with a publication

time span from 2020 to 2021. Keywords used in the search: ["anxiety" or "sleep quality" or "sleep disturbances" or "COVID-19" or "patients"] and ["progressive muscle relaxation"].

Results: Based on the search result, we found three related articles: two randomized controlled trials and one observational study. The studies examined the effectiveness of PMR to improve anxiety and sleep quality in hospitalized COVID-19 patients. In the results of the three studies, PMR was effective in improving anxiety symptoms and sleep quality in COVID-19 patients.

Conclusion: Considering not least of hospitalized COVID-19 patients who experienced anxiety and sleep disturbances, PMR as a non-pharmacological intervention can be implemented, because it is easy to perform and proven effective in reducing anxiety and sleep disturbances.
\end{abstract}

Keywords: Anxiety, COVID-19, Progressive Muscle Relaxation, Sleep Disturbance, Sleep Quality

Cite this Article: Ihsan, M., Sari, L.P.M.M., Wijaya, T.F., Saputri, D.M. 2021. The Effectiveness of Progressive Muscle Relaxation in Reducing Anxiety and Sleep Disturbances in Hospitalized COVID-19 Patients: A Narrative Review. Physical Therapy Journal of Indonesia 2(2): 36-40. DOI: 10.51559/ptji.v2i2.31

'Bachelor and Professional Program of Physical Therapy, College of Medicine, Universitas Udayana, Bali, Indonesia

\section{*Corresponding to:}

Muammar Ihsan, Bachelor and Professional Program of Physical Therapy, College of Medicine, Universitas Udayana, Bali, Indonesia; muammarihsan10@gmail.com

Received : 2021-08-05 Accepted : 2021-10-15 Published: 2021-12-02

\section{INTRODUCTION}

Since it was first discovered in Wuhan, Hubei Province at the end of 2019, Coronavirus disease (COVID-19) has spread rapidly and massively from China to the rest of the world. ${ }^{1}$ On March 11, 2020, the World Health Organization (WHO) declared COVID-19 as a global pandemic. ${ }^{2}$ As of early August 2021, COVID-19 has infected about 198 million people and caused 4.2 million deaths. ${ }^{3}$ Common symptoms of COVID-19 include cough, fever, fatigue, loss of the sense of taste or smell, sore throat, and headache, as well as more serious symptoms such as shortness of breath and chest pain. The worsening of these symptoms can lead to pneumonia, respiratory failure, multiorgan dysfunction, and even death. ${ }^{4,5}$

Besides physical symptoms, many of the hospitalized COVID-19 patients also suffered from psychiatric symptoms. A meta-analysis study by Xie (2021) revealed that COVID-19 patients could experience psychiatric symptoms from the acute to the recovery phase. ${ }^{6}$ Another metaanalysis by Deng (2020) which aimed to produce a comprehensive picture of the mental health status of COVID-19 patients, included 31 studies and found that $47 \%$ of COVID-19 patients experienced anxiety and 34\% experienced sleep disturbances. ${ }^{7}$ Several previous studies have stated that psychiatric responses such as anxiety and excessive sleep disturbances can interfere with patients in carrying out daily activities, affecting physical health and outcomes. ${ }^{8}$ Based on these problems, intervention to reduce psychiatric symptoms such as anxiety and sleep disturbances in COVID-19 patients is indispensable.

Treatment of the psychiatric symptoms commonly used sedative, hypnotic, and anti-anxiety drugs. However, these drugs have side effects and the risk of dependence, so non-pharmacological intervention is needed as an alternative to treat anxiety and sleep disturbances. ${ }^{9}$ In 1938, Jacobson developed an intervention called progressive muscle relaxation (PMR). Several previous studies showed 
PMR could provide various benefits in patients with chronic obstructive pulmonary disease (COPD), such as reducing muscle strain, switching attention to reduce pain, and sensitivity to fatigue. In the same population, the acute effects of PMR can improve pulse rate, respiration rate, dyspnea, and blood pressure. Also, related to the issues discussed in this review, PMR that emphasizes on patient self-control can reduce anxiety levels and facilitate COPD patients to sleep better. So, it is important to include PMR intervention in patients who have anxiety and sleep problems. ${ }^{10-12}$ Therefore, this study was conducted to determine the effectiveness of PMR in COVID-19 patients who experienced anxiety and sleep disturbances.

\section{METHODS}

We conducted a narrative review, finding for studies through advanced searching on the PubMed and Google Scholar database with a publication time span from 2020 to 2021. Keywords used in the search: ["anxiety" or "sleep quality" or "sleep disturbances" or "COVID-19" or "patients"] and ["progressive muscle relaxation"]. The types of studies searched include randomized controlled trials, observational studies, and case reports in English with available full text.

\section{RESULTS}

Based on the search results on the PubMed and Google Scholar database, we obtained three studies related to the topic: two randomized controlled trials and one observational study. The studies examined the effectiveness of PMR to improve anxiety and sleep quality in COVID-19 patients undergoing hospitalization. In the sample selection, Xiao (2020) excluded patients who were diagnosed with mental illness or taking sedation and antianxiety drugs before hospitalization. While two other studies did not explain the exclusion of patients with pre-existing mental illnesses. But, Liu (2020) kept including hospitalized patients who were taking hypnotic drugs to the experimental and control group without a significant difference in number between groups. The summary of the studies can be seen in Table 1 .

Liu (2020) found that progressive muscle relaxation could improve sleep quality and reduce anxiety among COVID-19 patients. The samples were divided into two groups, the control group and the experimental group, in which the experimental group were given PMR training. Measurement of anxiety using The State-Trait Anxiety Inventory (STAI) and sleep quality using Sleep State SelfRating Scale (SRSS). In both groups, the sleep quality score before the intervention had no significant difference $(P=0.838)$, but after the intervention, there was a significant difference between the groups $(P<0.001)$. In the measurement of anxiety, it was found that the two groups did not have a significant difference before the intervention $(P=0.730)$ and the average anxiety score became significant after the intervention $(P<0.001)$. The improvement in anxiety rates and sleep quality were better in the experimental group. ${ }^{13}$

Another study by Xiao (2020) which has a similar purpose, included 79 COVID-19 patients in the research and were divided into two groups, observation and control groups. The control group performed body movement, and the observation group received PMR training for a week. Whereas, the observation group performed PMR training 30 minutes before getting up and 30 minutes before going to bed, and exercise details were displayed using a 15-minutes video. The outcome measurements were done before and after intervention in the two groups using The Pittsburgh Sleeps Quality Index Scale (PSQI), The Patient Health Questionnaire (PHQ-9), and The Generalized Anxiety Disorder (GAD-7). There was no significant difference in PSQI, PHQ-9, and GAD-7 among the two groups before intervention. The difference between groups was significantly seen after the intervention in which the observation group had better scores in PSQI, PHQ-9, and GAD-7 $(P<0.05){ }^{14}$

Özlü (2021) also examined the effectiveness of PMR on anxiety levels and sleep quality of COVID-19 patients. The included COVID-19 patients were in stable condition, did not have visual and hearing impairments, and could perform PMR. Participants in the experimental group then followed the PMR instructions through TV from the given $\mathrm{CD}$. Evaluation of anxiety levels and sleep quality in this study used STAI and The RichardsCampbell Sleep Questionnaire (RCSQ). However, in STAI, only State Anxiety Scale (SAS) section in the questionnaire was used, which determines a person's feelings of anxiety at certain specific times and conditions. After undergoing the PMR training, the experimental group had better SAS and RCSQ scores. The SAS post-test scores of the experimental group were significantly better than the pre-test and control groups. Meanwhile, the RCSQ score presented in the study results was only the posttest score between the two groups, in which the experimental group has a significantly better RCSQ post-test score. ${ }^{15}$

\section{DISCUSSION}

The COVID-19 outbreak which first appeared at the end of 2019 caused various disadvantages, one 
of which was psychiatric problems such as serious anxiety that closely related to sleep disturbances, especially in confirmed patients. ${ }^{16,17}$ There are several factors that cause these problems, including patients' feelings of life-threatening illnesses, frustration on conditions they are in, and fear of the virus will infect their family members. In addition, the discomfort and pain of COVID-19 symptoms and isolation from family members or relatives can also increase the risk of anxiety and sleep disturbances. ${ }^{6,16}$

Both anxiety and sleep disturbances potentially cause psychological stress which could worsen the COVID-19 patient's condition. Psychological stress is one of the factors that increase concentrations of pro-inflammatory markers such as C-reactive protein (CRP) and Interleukin-6 (IL-6). ${ }^{18-20}$ High concentrations of CRP and IL-6 are strongly correlated with adverse outcomes and the severity of COVID-19. ${ }^{21}$ While physiologically, one implication of prolonged anxiety and sleep disturbances is elevated blood pressure. ${ }^{22-24}$ COVID-19 patients with elevated blood pressure have a higher relative risk of mortality than patients without high blood pressure. $^{25}$

Treatment of anxiety and sleep disturbances in COVID-19 patients is usually done with pharmacological treatment. The most used drugs classtoimprovethesesymptomsareBenzodiazepines (Estazolam, Flurazepam, Quazepam, Temazepam, and Triazolam). ${ }^{26,27}$ Benzodiazepines are normally administered only for short-term use. However, this drug class has some side effects that can aggravate respiratory function such as respiratory depression,

Table 1. Summary of the reviewed studies

\begin{tabular}{|c|c|c|c|c|}
\hline Author & $\begin{array}{l}\text { Type of Study and } \\
\text { Sample Size }\end{array}$ & Objective and Outcome Measures & Protocol & Results \\
\hline $\begin{array}{l}\text { Liu } \\
(2020)^{13}\end{array}$ & $\begin{array}{l}\text { RCT ( } 51 \text { pa- } \\
\text { tients confirmed } \\
\text { COVID-19: } 25 \\
\text { patients on experi- } \\
\text { mental group and } 26 \\
\text { patients on control } \\
\text { group). }\end{array}$ & $\begin{array}{l}\text { To explore the effects of progressive } \\
\text { muscle relaxation on anxiety and sleep } \\
\text { quality of COVID-19 patients. } \\
\text { STAI to evaluate patient's anxiety state. } \\
\text { SRSS to evaluate patient's sleep state. }\end{array}$ & $\begin{array}{l}\text { Experimental group: received } \\
\text { PMR with deep breathing (Ja- } \\
\text { cobson's relaxation techniques) } \\
\text { that performed } 20-30 \text { min/day } \\
\text { for } 5 \text { days of training. PMR was } \\
\text { performed in supine position with } \\
\text { 10-15s of muscle tension followed } \\
\text { by relaxation process in } 15-20 \text { s, } \\
\text { each muscle group repeated } 3 \\
\text { times in sequence. } \\
\text { Control group: received routine } \\
\text { care and treatment. }\end{array}$ & $\begin{array}{l}\text { The experimental group } \\
\text { had a better score in } \\
\text { STAI }(P<0.001) \text { and } \\
\text { SRSS }(P<0.001) \text {, which } \\
\text { was statistically signif- } \\
\text { icant compared to the } \\
\text { control group. }\end{array}$ \\
\hline $\begin{array}{l}\text { Xiao } \\
(2020)^{14}\end{array}$ & $\begin{array}{l}\text { Observational study } \\
\text { ( } 79 \text { COVID-19 } \\
\text { patients: } 39 \text { patients } \\
\text { on observation group } \\
\text { and } 40 \text { patients on } \\
\text { control group). }\end{array}$ & $\begin{array}{l}\text { To investigate the effects of an inter- } \\
\text { vention on negative emotions and } \\
\text { sleep quality of COVID-19 patients } \\
\text { through progressive muscle relaxation } \\
\text { training. } \\
\text { PSQI to evaluate patient's sleep quality } \\
\text { before and after the intervention. } \\
\text { GAD-7 to evaluate patient's anxiety } \\
\text { status. } \\
\text { PHQ-9 to evaluate patient's depression } \\
\text { status. }\end{array}$ & $\begin{array}{l}\text { Observation group: } 30 \text { minutes of } \\
\text { PMR training before getting up } \\
\text { early, and } 30 \text { minutes before going } \\
\text { to bed for } 1 \text { week. } \\
\text { Control group: performed a body } \\
\text { movement in bed only. }\end{array}$ & $\begin{array}{l}\text { The scores of GAD-7, } \\
\text { PHQ-9, and PSQI in } \\
\text { the observation group } \\
\text { after intervention were } \\
\text { all lower than those in } \\
\text { the control group }(P< \\
0.05) \text {, with a statistically } \\
\text { significant difference. }\end{array}$ \\
\hline $\begin{array}{l}\text { Özlü } \\
(2021)^{15}\end{array}$ & $\begin{array}{l}\text { RCT ( } 67 \text { pa- } \\
\text { tients confirmed } \\
\text { COVID-19: } 33 \\
\text { patients on experi- } \\
\text { mental group and } 34 \\
\text { patients on control } \\
\text { group). }\end{array}$ & $\begin{array}{l}\text { To investigate the effectiveness of PMR } \\
\text { exercise on anxiety levels and sleep } \\
\text { quality of COVID-19 patients. } \\
\text { SAS (subsection of STAI) to evaluate } \\
\text { state anxiety levels. } \\
\text { RCSQ to evaluate patient's perceptions } \\
\text { of sleep. }\end{array}$ & $\begin{array}{l}\text { Experimental group: watched } \\
\text { PMR exercise video from the } \\
\text { provided CD. The CD displayed } \\
\text { the PMR procedure with music } \\
\text { to help the patient relax for } 20-30 \\
\text { minutes, which was performed } \\
\text { twice a day for } 5 \text { days. } \\
\text { Control group: only received } \\
\text { routine care. }\end{array}$ & $\begin{array}{l}\text { The experimental group } \\
\text { showed better post-test } \\
\text { mean scores on SAS } \\
\text { (subsection STAI) }(P< \\
0.05) \text { and RCSQ }(P< \\
0.05) \text {. }\end{array}$ \\
\hline
\end{tabular}

CD: Compact Disc; GAD-7: The Generalized Anxiety Disorder; PHQ-9: The Patient Health Questionnaire; PMR: Progressive Muscle Relaxation; PSQI: The Pittsburgh Sleeps Quality Index Scale; RCSQ: The Richards-Campbell Sleep Questionnaire; RCT: Randomized Controlled Trial; SAS: State Anxiety Scale; SRSS: Sleep State SelfRating Scale; STAI: The State-Trait Anxiety Inventory; TV: Televis ${ }^{\text {ion }}$ 
hypoventilation, delirium, and may cause suicidal ideation as well. Hence, the use of the drug needs to be closely monitored. ${ }^{26}$ As an alternative, nonpharmacological intervention is needed to reduce anxiety and sleep disturbances.

Some previous studies have been conducted to investigate the effectiveness of PMR in reducing anxiety levels and sleep disturbances. Yilmaz (2019) in his systematic review which identified the use of PMR in COPD patients, found that PMR can improve anxiety symptoms and sleep quality. ${ }^{28}$ In different populations, Aksu (2018) examined the effects of PMR intervention on postoperative pulmonary resection patients. The results showed that PMR intervention after 1 week could significantly improve patients' quality of sleep in the experimental group. ${ }^{29}$ The effectiveness of PMR intervention in reducing anxiety and sleep disturbances in these studies indicate that this intervention is also possible to provide similar outcomes in hospitalized COVID-19 patients.

The concept used in PMR is the activation of the neuronal system through the corticospinal and spinocerebellar tracts by contracting and relaxing the muscles progressively until complete relaxation is fulfilled. In the corticospinal tract pathway, muscle contraction and relaxation are started in the cerebral cortex and cerebellum. Whereas in the spinocerebellar tract, proprioceptive stimulation in the form of resistance to contraction and the process of muscle relaxation will be sent to the cerebellum through the spinal cord and brain stem. Repeating PMR will reduce physiological tension, resulting in physical relaxation. In addition, PMR trains the patient's perception to control their emotions. This helped the patient to improve anxiety levels and to sleep better. ${ }^{10,12,30}$

To date, only three studies have tested the effect of PMR on improving anxiety symptoms and sleep quality of hospitalized COVID-19 patients. Liu (2020) and Özlü (2021) both provided PMR intervention to patients for 5 days. However, PMR instructions in Liu's study were carried out by medical staff via the telephone system of the hospital where the patient was hospitalized, whereas, in Özlü's study, patients only practised PMR by watching video from the given CD. Slightly different from the two studies, Xiao (2020) provided PMR intervention with more comprehensive, in which patients performed PMR by viewing demonstration videos while being accompanied by nurses. Patients carried out PMR for 7 days. In the results of the three studies, PMR was effective in improving anxiety symptoms and sleep quality in COVID-19 patients. ${ }^{13-15}$

\section{LIMITATION}

Three studies have shown that PMR can improve anxiety levels and sleep quality of hospitalized COVID-19 patients. However, there are some limitations to these studies. First, only Liu (2020) and Xiao (2020) described the PMR procedure in their study, while Özlü (2021) did not. His study only mentioned that patients followed the PMR instructions through the $\mathrm{CD}$ provided. In terms of clinical characteristics of COVID-19 patients, only Liu study presented a comparison between the two groups before the intervention, but none of the three studies evaluated clinical symptoms after PMR. Evaluation of the patient's clinical status is needed to determine whether there is an adverse effect of PMR on clinical symptoms. Last, three studies included relatively few participants and only took from the same institution or hospital, thus allowing for location bias. Further research with a larger number of participants who come from several isolation places is needed so that the results can be generalized.

\section{CONCLUSION}

Considering not least of hospitalized COVID-19 patients who experienced anxiety and sleep disturbances, PMR as a non-pharmacological intervention can be implemented, because it is easy to perform and proven effective in reducing anxiety and sleep disturbances.

\section{CONFLICT OF INTEREST}

The authors state that there are not conflict of interests.

\section{ACKNOWLEDGEMENT}

The authors would like to thank all parties involved in making this narrative review.

\section{AUTHOR CONTRIBUTIONS}

MI compiled the study design and drafted the manuscript; TFW and LPMMS collected the literature and drafted the manuscript; DMS reviewed and edited the manuscript.

\section{REFERENCES}

1. McIntosh K, Hirsch MS, Bloom A. Coronavirus disease 2019 (COVID-19): Epidemiology, virology, and prevention. Lancet. Infect. Dis. 2020;1:2019-20.

2. Cucinotta D, Vanelli M. WHO declares COVID-19 a pandemic. Acta Bio Medica: Atenei Parmensis. 2020;91(1):157.

3. World Health Organization. WHO Coronavirus (COVID-19) Dashboard [Internet]. 2021 [cited 2021 
August 3]. Available from: https://covid19.who.int/

4. Singhal T. A review of coronavirus disease-2019 (COVID-19). The indian journal of pediatrics. 2020;87(4):281-6.

5. World Health Organization. COVID-19 symptoms [Internet]. [cited 2021 June 25]. Available from: https:// www.who.int/indonesia/news/novel-coronavirus/newinfographics/covid-19-symptoms

6. Xie Q, Liu XB, Xu YM, Zhong BL. Understanding the psychiatric symptoms of COVID-19: a meta-analysis of studies assessing psychiatric symptoms in Chinese patients with and survivors of COVID-19 and SARS by using the Symptom Checklist-90-Revised. Translational Psychiatry. 2021;11(1):1-0.

7. Deng J, Zhou F, Hou W, Silver Z, Wong CY, Chang O, Huang E, Zuo QK. The prevalence of depression, anxiety, and sleep disturbances in COVID-19 patients: a metaanalysis. Annals of the New York Academy of Sciences. 2020;1486(2021):90-111

8. Hu Y, Chen Y, Zheng Y, You C, Tan J, Hu L, Zhang Z, Ding L. Factors related to mental health of inpatients with COVID-19 in Wuhan, China. Brain, behavior, and immunity. 2020;89:587-93.

9. Ding H, He F, Lu YG, Hao SW, Fan XJ. Effects of nondrug interventions on depression, anxiety and sleep in COVID-19 patients: a systematic review and meta-analysis. Eur Rev Med Pharmacol Sci. 2021;25(2):1087-96.

10. McCallie MS, Blum CM, Hood CJ. Progressive muscle relaxation. Journal of Human Behavior in the Social Environment. 2006;13(3):51-66.

11. Chegeni PS, Gholami M, Azargoon A, Pour AH, Birjandi $\mathrm{M}$, Norollahi $\mathrm{H}$. The effect of progressive muscle relaxation on the management of fatigue and quality of sleep in patients with chronic obstructive pulmonary disease: A randomized controlled clinical trial. Complementary therapies in clinical practice. 2018;31:64-70.

12. Volpato E, Banfi P, Rogers SM, Pagnini F. Relaxation techniques for people with chronic obstructive pulmonary disease: a systematic review and a meta-analysis. EvidenceBased Complementary and Alternative Medicine. 2015;2015.

13. Liu K, Chen Y, Wu D, Lin R, Wang Z, Pan L. Effects of progressive muscle relaxation on anxiety and sleep quality in patients with COVID-19. Complementary therapies in clinical practice. 2020;39:101132.

14. Xiao CX, Lin YJ, Lin RQ, Liu AN, Zhong GQ, Lan CF. Effects of progressive muscle relaxation training on negative emotions and sleep quality in COVID-19 patients: A clinical observational study. Medicine. 2020;99(47):e23185.

15. Özlü İ, Öztürk Z, Özlü ZK, Tekin E, Gür A. The effects of progressive muscle relaxation exercises on the anxiety and sleep quality of patients with COVID-19: A randomized controlled study. Perspectives in Psychiatric Care. 2021:1-7.

16. Zhang GY, Liu Q, Lin JY, Yan L, Shen L, Si TM. Mental health outcomes among patients from Fangcang shelter hospitals exposed to coronavirus disease 2019: An observational cross-sectional study. Chronic diseases and translational medicine. 2021;7(1):57-64.
17. Dai LL, Wang X, Jiang TC, Li PF, Wang Y, Wu SJ, Jia LQ, Liu M, An L, Cheng Z. Anxiety and depressive symptoms among COVID-19 patients in Jianghan Fangcang Shelter Hospital in Wuhan, China. PloS one. 2020;15(8):e0238416.

18. Ono BH, Souza JC. Sleep and immunity in times of COVID-19. Revista da Associação Médica Brasileira. 2020;66(Suppl 2):143-147.

19. Wium-Andersen MK, Ørsted DD, Nielsen SF, Nordestgaard BG. Elevated C-reactive protein levels, psychological distress, and depression in 73131 individuals. JAMA psychiatry. 2013;70(2):176-84.

20. Ting EY, Yang AC, Tsai SJ. Role of interleukin-6 in depressive disorder. International journal of molecular sciences. 2020;21(6):2194.

21. El-Shabrawy M, Alsadik ME, El-Shafei M, Abdelmoaty AA, Alazzouni AS, Esawy MM, Shabana MA. Interleukin-6 and C-reactive protein/albumin ratio as predictors of COVID-19 severity and mortality. The Egyptian Journal of Bronchology. 2021;15(1):5.

22. Wang M, Hu C, Zhao Q, Feng R, Wang Q, Cai H, Guo Z, Xu K, Luo W, Guo C, Zhang S. Acute psychological impact on COVID-19 patients in Hubei: a multicenter observational study. Translational psychiatry. 2021;11:133.

23. Pan Y, Cai W, Cheng Q, Dong W, An T, Yan J. Association between anxiety and hypertension: a systematic review and meta-analysis of epidemiological studies. Neuropsychiatric disease and treatment. 2015;11:1121-30.

24. Calhoun DA, Harding SM. Sleep and hypertension. Chest. 2010;138(2):434-43.

25. Gao C, Cai Y, Zhang K, Zhou L, Zhang Y, Zhang X, Li Q, Li W, Yang S, Zhao X, Zhao Y. Association of hypertension and antihypertensive treatment with COVID-19 mortality: a retrospective observational study. European heart journal. 2020;41(22):2058-66.

26. US Pharmacist. The Impact of COVID-19 on Mental Health in Patients [Internet]. 2021 [cited 2021 July 15] Available from: https://www.uspharmacist.com/article/ the-impact-of-covid19-on-mental-health-in-patients

27. Rismanbaf A. Insomnia drug therapy in COVID-19 patients; a letter to editor. Caspian Journal of Internal Medicine. 2020;11(Suppl 1):583-584.

28. Yilmaz CK, Kapucu S. Using Progressive Relaxation Exercise in Chronic Obstructive Lung Disease: Systematic Review. Journal of Hacettepe University Faculty of Nursing. 2019;6(2):65-74.

29. Aksu NT, Erdogan A, Ozgur N. Effects of progressive muscle relaxation training on sleep and quality of life in patients with pulmonary resection. Sleep and Breathing. 2018;22(3):695-702

30. Toussaint L, Nguyen QA, Roettger C, Dixon K, Offenbächer M, Kohls N, Hirsch J, Sirois F. Effectiveness of Progressive Muscle Relaxation, Deep Breathing, and Guided Imagery in Promoting Psychological and Physiological States of Relaxation. Evidence-Based Complementary and Alternative Medicine. 2021;2021

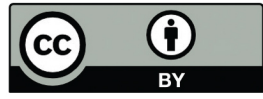

This work is licensed under a Creative Commons Attribution 